\title{
Wnt3a deficiency irreversibly impairs hematopoietic stem cell self-renewal and leads to defects in progenitor cell differentiation
}

\author{
Tiago C. Luis, ${ }^{1}$ Floor Weerkamp, ${ }^{1}$ Brigitta A. E. Naber, ${ }^{1}$ Miranda R. M. Baert, ${ }^{1}$ Edwin F. E. de Haas, ${ }^{1}$ Tatjana Nikolic, ${ }^{2}$ \\ Sjanneke Heuvelmans, ${ }^{1}$ Ronald R. De Krijger, ${ }^{3}$ Jacques J. M. van Dongen, ${ }^{1}$ and Frank J. T. Staal ${ }^{1}$ \\ Departments of ${ }^{1}$ Immunology, ${ }^{2}$ Pulmonary Medicine, and ${ }^{3}$ Pathology, ErasmusMC, Erasmus University Medical Center, Rotterdam, The Netherlands
}

\begin{abstract}
Canonical Wnt signaling has been implicated in various aspects of hematopoiesis. Its role is controversial due to different outcomes between various inducible Wnt-signaling loss-of-function models and also compared with gain-of-function systems. We therefore studied a mouse deficient for a Wnt gene that seemed to play a nonredundant role in hematopoiesis. Mice lacking Wnt3a die prenatally around embryonic day (E) 12.5 , allowing fetal hematopoiesis to be studied using in
\end{abstract}

vitro assays and transplantation into irradiated recipient mice. Here we show that Wnt3a deficiency leads to a reduction in the numbers of hematopoietic stem cells (HSCs) and progenitor cells in the fetal liver (FL) and to severely reduced reconstitution capacity as measured in secondary transplantation assays. This deficiency is irreversible and cannot be restored by transplantation into Wnt3a competent mice. The impaired long-term repopulation capacity of Wnt3a-I- HSCs could not be explained by altered cell cycle or survival of primitive progenitors. Moreover, Wnt3a deficiency affected myeloid but not B-lymphoid development at the progenitor level, and affected immature thymocyte differentiation. Our results show that Wnt3a signaling not only provides proliferative stimuli, such as for immature thymocytes, but also regulates cell fate decisions of HSC during hematopoiesis. (Blood. 2009;113:546-554)

\section{Introduction}

Hematopoietic stem cells (HSCs) are responsible for the continuous production of blood cells and consequently help to sustain immune function. This is achieved by their unique capacity to self-renew and ability to differentiate into all blood lineages. Several studies have implicated the Wnt-signaling pathway in the regulation of these processes, but its exact role is still not completely understood. ${ }^{1,2}$

Upon binding of a Wnt protein to a Frizzled receptor and to a LRP5/6 coreceptor, an elaborate signaling route leads to cytoplasmatic accumulation and subsequent nuclear translocation of $\beta$ catenin, the key mediator of the Wnt-signaling pathway. In the absence of a Wnt protein, the levels of $\beta$-catenin are kept very low by the action of the so-called destruction complex consisting of the casein kinase I (CKI) and glycogen synthase kinase $3 \beta$ (GSK-3 $\beta$ ) serine/threonine kinases, the tumor suppressor protein adenomatous polyposis coli (APC) and the scaffolding protein Axin. Phosphorylation of $\beta$-catenin by CKI and GSK-3 $\beta$ leads to its ubiquitination and subsequent breakdown in the proteossome. Activation of the Wnt pathway by a Wnt ligand results in inactivation of GSK-3 $\beta$ and consequent translocation of $\beta$-catenin to the nucleus. In the nucleus, $\beta$-catenin binds to members of the Tcf/Lef transcription factors family, thereby converting these proteins from transcriptional repressors into transcriptional activators. $^{3}$

The first evidence for a role of Wnt proteins in hematopoiesis was reported in studies showing that stromal cell lines transduced with Wnt1, Wnt5a, and Wnt10b have an in vitro stimulatory effect on mouse ${ }^{4}$ and human ${ }^{5}$ hematopoietic progenitors.

Using Tcf1/Lef-GFP reporter assays, Wnt signaling was shown to be active in the highly HSCs enriched $\mathrm{Lin}^{-} \mathrm{Sca} 1^{+} \mathrm{c}-\mathrm{Kit}^{+}$(LSK) population, both in vivo as well as in vitro after stimulation with purified Wnt3a. ${ }^{6}$ Furthermore, Wnt3a treatment in vitro resulted in increased proliferation of LSK cells along with the maintenance of an immature phenotype and led to increased self-renewal as determined by transplantation assays. ${ }^{7}$ Retroviral expression of a constitutively active form of $\beta$-catenin in Bcl2-transgenic LSK cells resulted in augmented multilineage repopulation capacity. In agreement, ectopic expression of the Wnt-signaling inhibitor Axin yielded opposite results. ${ }^{6}$ However, subsequent gain- and loss-offunction approaches to further elucidate the role of Wnt signaling in HSCs yielded contradictory results. Two independent studies using a conditional mouse model to express a stabilized form of $\beta$-catenin showed impaired multilineage differentiation and a transient increase in stem cell numbers, followed by exhaustion of the HSC pool, observed by failure to repopulate lethally irradiated recipients. ${ }^{89}$ Therefore, the role of Wnt signaling in HSC biology is currently controversial. Besides this, reciprocal approaches to conditionally inactivate $\beta$-catenin in HSCs also showed contradictory results and brought further controversy, with some of these studies showing normal hematopoiesis and stem cell activity in the combined absence of $\beta$-catenin and its homologue plakoglobin. ${ }^{10-13}$ These issues are reviewed in more detail elsewhere. ${ }^{14}$

The functions of several Wnt genes have been investigated by targeted mutations in the mouse. These led to specific developmental defects, which are lethal early during embryonic development or shortly after birth. Mice carrying a null allele of Wnt $3 a$ have been generated by McMahon and coworkers. Wnt3a homozygous mutant embryos die around embryonic day (E) 12.5 of the embryonic development. These embryos lack caudal somites, have disrupted notochords and exhibit anomalies of the central nervous system. ${ }^{15}$
Submitted June 17, 2008; accepted September 8, 2008. Prepublished online as Blood First Edition paper, October 2, 2008; DOI 10.1182/blood-2008-06-163774.

The publication costs of this article were defrayed in part by page charge payment. Therefore, and solely to indicate this fact, this article is hereby marked "advertisement" in accordance with 18 USC section 1734.

(C) 2009 by The American Society of Hematology 
The hematopoietic system of these embryos has not been studied yet. However, the fact that Wnt3a promotes proliferation of $\mathrm{HSCs}^{7}$ and pro-B cells, ${ }^{16}$ and the high expression in the thymic stroma ${ }^{17}$ make the Wnt $3 a$ gene of interest. In addition, Wnt $3 a^{-1-}$ embryos are morphologically highly similar to Tcfl/Lefl double-deficient embryos, ${ }^{18,19}$ suggesting comparable defects in the hematopoietic system $^{20}$ of both strains. For these reasons we decided to investigate the hematopoietic system of Wnt $3 a^{-1-}$ embryos.

Here we demonstrate that Wnt3a deficiency leads to a reduction in the numbers of hematopoietic stem and progenitor cells in the fetal liver (FL). Besides this, HSCs are functionally affected as purified LSK cells show severely reduced reconstitution capacity measured by secondary transplantation assays. This deficiency is irreversible since transplantation into wild-type (Wt) recipient mice could not restore HSC function, suggesting a role for Wnt3a in the establishment of a HSC-specific genetic program. Moreover Wnt3a deficiency affected myeloid but not lymphoid development at the progenitor level and early stages of T-lymphoid development in the thymus.

Our data provide genetic evidence for the involvement of a specific Wnt protein in HSC self-renewal, suggesting that modulation of Wnt signaling in stem cells or in their environment may be beneficial for stem cell therapies, transplantation, and regenerative medicine applications (Wilmington, MA).

\section{Methods}

\section{Mice}

Wnt3a heterozygous mice were bred and maintained in the Erasmus Medical Center animal facility, in accordance with the legal regulations in The Netherlands and with the approval of the Dutch animal ethical committee, the DEC.

Mice heterozygous for the Wnt3a mutation were kindly provided by T. Yamaguchi (National Cancer Institute-Frederick, Frederick, MD) and were backcrossed to C57B1/6. Genotyping was performed as described. ${ }^{15}$ To obtain Wnt $3 \mathrm{a}^{-1-}$ embryos, Wnt3a heterozygous mice were put together in the afternoon and checked for vaginal plug the next morning. The time at which the vaginal plug was observed was considered E0.5. Embryos were analyzed at E12.5. C57B1/6-Ly5.1 mice were purchased from Charles River Laboratories (Wilmington, MA).

\section{Flow cytometry and cell sorting}

For flow cytometric analyses and cell sorting, cells were stained with monoclonal antibodies against the following molecules: B220 (Ra3-6B2), CD3 (145-2C11), CD4 (L3T4), CD8 (53-6.7), CD11b/Mac1 (M1/70), CD11c (HL3), CD19 (ID3), CD43 (S7), CD45.1/Ly5.1 (A20), CD45.2/ Ly5.2,(104) CD71 (C2), CD117/c-Kit (2B8), CD127/IL-7R $\alpha$ (SB/199), CD135/Flt3 (A2F10.1), F4/80 (BM8), GR1 (RB6-8C5), IgM (R6-60.2), NK1.1 (PK136), Sca1 (E13-161.7) and Ter-119 all from Becton Dickinson/ Pharmingen (San Jose, CA); CD34 (RAM34) and Fc $\gamma$ RII/III(93) from eBioscience (San Diego, CA); activated Notch1 (mN1A) from Abcam (Cambridge, MA). Antibodies were used either directly conjugated or biotinylated. For secondary detection streptavidin conjugated with PE-Cy7 or APC-Cy7 was used. 7AAD (Pharmingen) or DAPI (Invitrogen, Carlsbad, CA)) were used for dead cells exclusion. Stained cells were measured with a FACSCalibur and/or a FACSCanto, sorted on a FACSAria (Becton Dickinson), and analyzed with FlowJo software (TreeStar, Ashland, OR). To analyze LSK in FL, antibodies for lineage markers included B220, CD4, CD11c, GR1, NK1.1 and Ter-119. When LSKs were analyzed in adult bone marrow (BM) antibodies against $\mathrm{CD} 11 \mathrm{~b}(\mathrm{Mac} 1)$ and $\mathrm{CD} 3$ were added to the lineage mix.

\section{Cell cycle and apoptosis}

Cell-cycle analysis of FL stem and progenitor cells was performed by staining for 60 minutes $37^{\circ} \mathrm{C}$ with Hoechst 33342 ((Invitrogen/Molecular Probes, Carlsbad, CA; $10 \mu \mathrm{g} / \mathrm{mL}$ ) in DMEM medium supplemented with Verapamil inhibitor (Sigma-Aldrich, St Louis, MO; $10 \mu \mathrm{M}$ ), 2\% FBS and $1 \mathrm{mM}$ HEPES (Invitrogen). Hoechst 33342 stained cells were than stained with flow cytometry antibodies. To analyze the percentage of apoptotic cells by flow cytometry, FL cells were stained with markers to define the LSK population (see "Flow cytometry and cell sorting") and subsequently stained with FITC-conjugated annexin V and 7AAD (Becton Dickinson/ Pharmingen) according to the manufacturer's instructions.

\section{Transplantation experiments}

For competitive transplantation assays, C57B1/6 Ly5.1 recipient mice (8-11 weeks old) were lethally irradiated $(9.5 \mathrm{~Gy})$. Four hundred sorted LSKs (Ly5.2) from Wt or Wnt3a $a^{-1-}$ E12.5 FLs were mixed with $2.5 \times 10^{5}$ total Ly5.1 FL cells (E12.5) to obtain 1:1 competition and intravenously injected in recipient mice. Repopulation, calculated as (percentage donor cells) $\times 100 /$ (percentage donor cells + percentage recipient cells), was evaluated at $4,8,10$, and 12 weeks after transplantation in peripheral blood by flow cytometry. The mice were killed 12 weeks after transplantation. For secondary transplantation, equal numbers of total BM cells from primary recipients that received Wt or Wnt $3 a^{-1-}$ LSKs were pooled and transplanted into lethally irradiated Ly5.1 secondary recipients. Peripheral blood from secondary transplanted mice was analyzed at 4, 8, and 12 weeks after transplantation. Thirteen weeks after transplantation, mice were killed and analyzed for reconstitution in BM, thymus, and spleen.

\section{In vitro methylcellulose colony assays}

For methylcellulose colony assays, FL cell suspensions were prepared in Iscove modified Dulbecco medium (IMDM) supplemented with 2\% FBS. CFU-C and CFU-E assays were performed with MethoCult M3434 (containing rmSCF $50 \mathrm{ng} / \mathrm{mL}$, rmIL-3 $10 \mathrm{ng} / \mathrm{mL}$, rhIL-6 $10 \mathrm{ng} / \mathrm{mL}$, and rhEPO $3 \mathrm{U} / \mathrm{mL}$ ) or M3334 (containing rhEPO $3 \mathrm{U} / \mathrm{mL}$ ), respectively, (from StemCell Technologies, Grenoble, France) in 35-mm dishes accordingly to manufacturer's instructions. All assays were done in triplicate. Colonies (> 30 cells) were counted after 7 days (CFU-C) or 3 days (CFU-E) of incubation at $37^{\circ} \mathrm{C}, 5 \% \mathrm{CO}_{2}$ and humidified atmosphere. CFU-Mix were defined as colonies containing at least 3 different cell types. May-Grunwald Giemsa stainings were performed to confirm identification of the colonies by morphology.

\section{Cocultures of FL cells with OP9 bone marrow stromal cell line}

Total FL cells were cultured in RPMI-1640 medium supplemented with $10 \%$ FBS, mrlL-7 (10 ng/mL) and mrSCF $(50 \mathrm{ng} / \mathrm{mL}$; both from R\&D Systems, Minneapolis, MN), for 24 hours to separate FL stroma from hematopoietic cells. Ten thousand to 50000 cells were then cultured on confluent layers of the OP9 BM stromal cell line in $\alpha$ MEM medium, also supplemented with FBS, mrIL-7, and mrSCF. After 7 to 16 days of incubation at $37^{\circ} \mathrm{C}$, cells were harvested and stained for flow cytometry.

\section{Histology and immunohistochemistry}

Six- $\mu \mathrm{m}$ tissue sections of frozen E12.5 embryos were fixed in acetone. For visualization of the different organ structures, sections were stained with hematoxylin-eosin (HE). To envisage thymic epithelium, sections were incubated with concentrated supernatant from a hybridoma producing the ER-TR4 antibody for thymic stromal cells, followed by a biotinylated rabbit anti-rat antibody (Dako, Glostrup, Denmark) and finally with avidin-biotin complex-horseradish peroxidase (Dako). Sections were incubated with 3-amino-9-ethylcarbazole (AEC) substrate (Dako) to detect peroxidase.

\section{Fetal thymic organ culture}

Fetal thymic lobes from Wt and Wnt $3 a^{-1-}$ E12.5 embryos were isolated and cultured on the top of a filter floating on medium (IMDM, 10\% FBS). After 
A

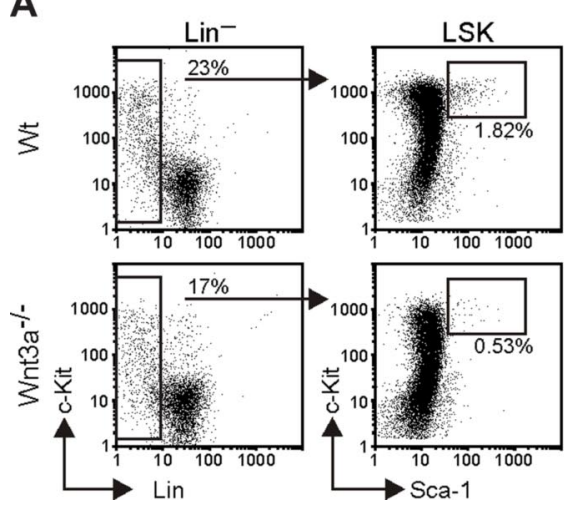

B

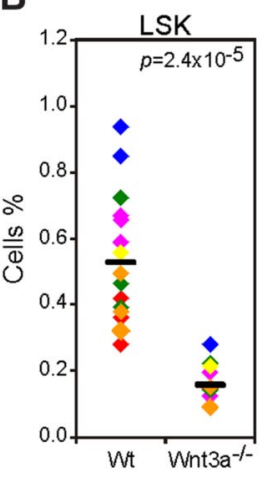

C

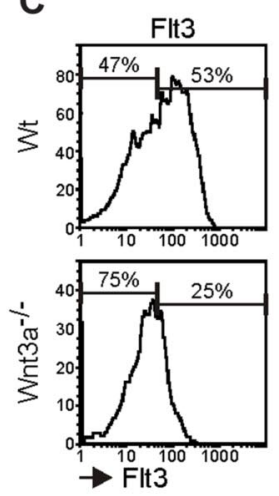

D

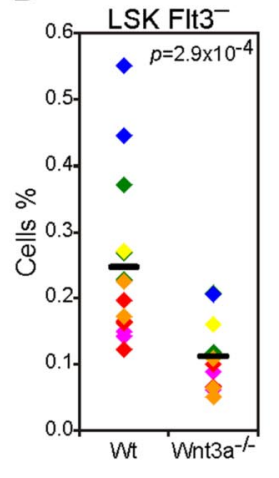

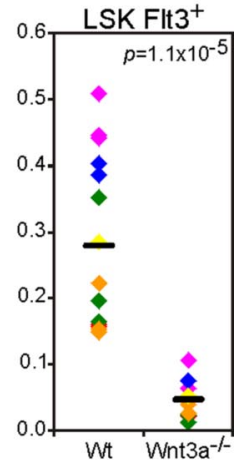

Figure 1. Wnt3a deficiency leads to a severe reduction in HSC (LSK Flt3 ${ }^{-}$) and multipotent progenitor (MPP, LSK Flt3 ${ }^{+}$) numbers. (A) Flow cytometry analysis of LSK $\left(\mathrm{Lin}^{-} \mathrm{Sca}^{+}{ }^{\mathrm{C}-\mathrm{Kit}^{+}}\right.$) population in Wt and Wnt3a ${ }^{-1-}$ FLs from E12.5 embryos. Lineage negative cells were electronically gated and analyzed for Sca1 and c-Kit expression. Percentage of Sca $1^{+} \mathrm{C}-\mathrm{Kit}^{+}$cells is indicated. (B) Percentage of LSK cells in total FL is strongly decreased. Data are from $16 \mathrm{Wt}$ and $11 \mathrm{Wnt} 3 \mathrm{a}^{-/-} \mathrm{FLs}$, belonging to 6 different litters identified by different colors. Mean values are presented as a dash. (C) Flow cytometry analysis of the Flt3 subsets in the LSK compartment. LSKs were electronically

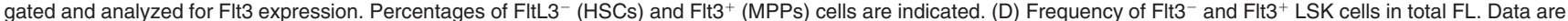
from $16 \mathrm{Wt}$ and $11 \mathrm{Wnt} 3 \mathrm{a}^{-/-}$FLs, belonging to 6 different litters identified by different colors. Mean values are presented as a dash. $P$ values are indicated in all graphs.

9 to 17 days of culture, cells were harvested and analyzed by flow cytometry.

\section{Results}

\section{Reduced numbers of HSCs in Wnt3a-l- E12.5 embryos}

The loss of Wnt3a leads to embryonic lethality around E12.5. Wnt $3 \mathrm{a}^{-1-}$ embryos harbor a severe phenotype with little or no caudal development posterior to forelimbs, disrupted notochord, and abnormal formation of ectopic neural tubes. ${ }^{15}$ After E12.5, recovery of viable $\mathrm{Wnt}_{3} \mathrm{a}^{-1-}$ embryos dramatically decreases, and therefore heterozygous mice were bred and the embryos analyzed at this age.

At E12.5 the FL is the major hematopoietic organ, which is colonized by progenitors from aorta-gonad-mesonephros (AGM) region, yolk sac and placenta, starting by late E9. ${ }^{21}$ The FLs from Wnt $3 \mathrm{a}^{-1-}$ and Wt embryos did not differ in the total cell numbers $\left(2.86 \times 10^{6} \pm 1.28 \times 10^{6}\right.$ in $\mathrm{Wnt}^{3} \mathrm{a}^{-1-}$ and $3.32 \times 10^{6} \pm 1.25 \times 10^{6}$ in Wt FLs; $p=.54$ ) and the total percentage of leukocytes (as determined by CD45 expression) did also not differ between Wt and Wnt $3 \mathrm{a}^{-1-}$ FLs (data not shown). Besides this, FLs were red, suggesting that the embryos were not anemic.

Murine HSCs are found in a rare population characterized by the absence of lineage markers and expression of Sca1 and c-Kit,

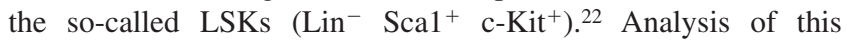
population in the FLs from $W n t 3 a^{-1-}$ embryos showed a marked

Table1. Total FL cell suspensions from embryonic day $12.5 \mathrm{Wt}$ or Wnt3a- ${ }^{-1-}$ embryos (Ly5.2) were prepared and the indicated numbers of cells were intravenously injected into sublethally irradiated Ly5.1 recipient mice

\begin{tabular}{lll}
\hline \multirow{2}{*}{$\begin{array}{l}\text { E12.5 FL } \\
\text { cells/mouse }\end{array}$} & \multicolumn{2}{c}{ Repopulated mice } \\
\cline { 2 - 3 } & \multicolumn{1}{c}{ Wt } & Wnt3a-/- \\
\hline $0.25 \times 10^{6}$ & $2 / 6^{*}(33 \%) \dagger$ & $0 / 6(0 \%)$ \\
$1 \times 10^{6}$ & $3 / 5(60 \%)$ & $0 / 3(0 \%)$ \\
$4 \times 10^{6}$ & $4 / 4(100 \%)$ & $3 / 3(100 \%)$ \\
\hline
\end{tabular}

Multilineage repopulation was confirmed by flow cytometry for all repopulated animals.

*Number of repopulated mice ( $>1 \%$ in peripheral blood) 12 weeks after transplantation per total number of mice receiving a transplantation.

†Correspondent frequencies of repopulated animals. reduction in the percentage of these cells (3- to 5-fold) comparing to Wt (Figure 1A,B). While in agreement with previous reports the Wt FLs contained $0.51 \%$ LSK, the Wnt $3 \mathrm{a}^{-/-}$FLs contained only $0.15 \%$ LSKs on average.

Different studies have shown that up-regulation of Flt3/Flk2 expression is accompanied by loss of HSC long-term reconstitution capacity in BM and FL. ${ }^{23-25}$ The analysis of the Flt3- (HSCs) and $\mathrm{Flt}^{+}$(multipotent progenitors; MPP) subsets within the LSK population revealed that, although the $\mathrm{Flt}^{+}$subset was more severely affected, both populations were strongly decreased indicating a HSC deficiency (Figure 1C,D). This quantitative difference led to a difference in actual stem cell-dependent repopulation of recipient mice. That is, when different numbers of E12.5 FL cells from Wt or Wnt $3 a^{-1-}$ embryos were transplanted into sublethally irradiated recipients $(6 \mathrm{~Gy})$, only the highest number of $W n t 3 a^{-1-}$ cells $\left(4 \times 10^{6}\right)$ could repopulate $(>1 \%$ donor contribution in peripheral blood) 3 of 3 recipient mice. By contrast, a 16-fold lower number of Wt cells transplanted $\left(0.25 \times 10^{6}\right.$ cells $)$ was able to repopulate 2 of 6 recipient mice (Table 1), while none of the mice (0 of 6) that received $W n t 3 a^{-1-}$ cells showed donor-derived reconstitution.

\section{HSC self-renewal is irreversibly impaired}

To test whether besides a severe quantitative reduction in HSC, these cells were also affected in their function, we performed competitive transplantation assays. For this, $400 \mathrm{LSKs}$ isolated by cell sorting from Wt or Wnt3a ${ }^{-1-}$ FLs (Ly5.2) were mixed with $2.5 \times 10^{5} \mathrm{Wt}$ total FL cells (Ly5.1), which were measured to also contain around $400 \mathrm{LSK}$, to have an approximately 1:1 competition. The cell mixtures were intravenously injected into Wt Ly5.1 recipient mice that were lethally irradiated. The chimerism was followed in peripheral blood at 4, 8, 10, and 12 weeks after transplantation. Both $\mathrm{Wt}$ and $\mathrm{Wnt} 3 \mathrm{a}^{-1-}$ cells were able to repopulate the primary recipients with comparable efficiency ( 7 of 8 mice repopulated $>1 \%$ with $\mathrm{Wt}$ cells and $3 / 4$ mice repopulated with $W_{n t 3 a^{-l-}}$ cells; Figure 2A). Besides this, 12 weeks after the beginning of the experiment, the analysis of BM of repopulated mice showed no significant difference in the percentage of total Ly5.2 (Figure 2B,C) and in the contribution toward the different lineages (data not shown). Analysis of the HSC compartment revealed a nonstatistically significant reduction in the frequency 
A

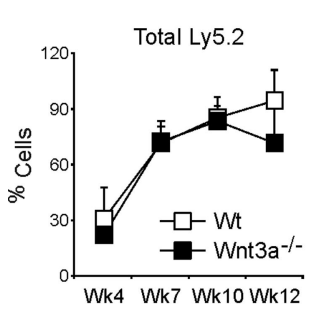

B

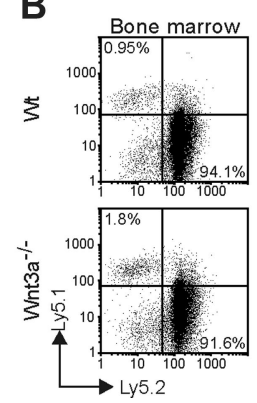

C

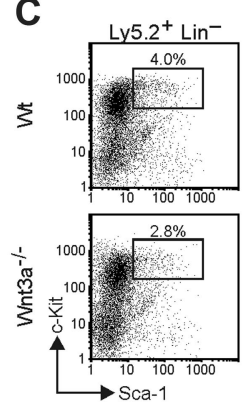

D

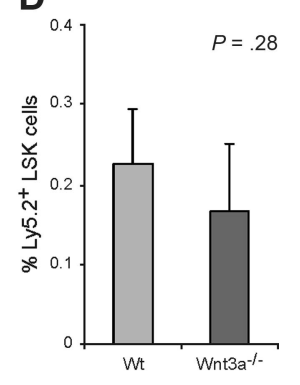

Figure 2. Wnt3a ${ }^{-1-}$ LSKs efficiently repopulate primary recipient mice in competitive assays. Lethally irradiated Ly5.1 mice were transplanted with sorted LSK cells (Ly5.2), from Wt or Wnt3a ${ }^{-1-}$ FLs, together with unfractionated FL cells (Ly5.1), to have a competition of approximately 1:1. (A) Repopulation efficiency (percentage of Ly5.2 cells) was analyzed in peripheral blood at the indicated time points. Graph shows mean plus or minus SD of 7 and 3 mice that received Wt and Wnt3a-l- LSKs, respectively. (B) Repopulation efficiency (percentage of Ly5.2 cells) was analyzed in BM of recipient mice at 12 weeks. Numbers in quadrants indicate the percentage of total Ly5.1 or Ly5.2 cells. (C) Analysis of the HSC compartment. Lin ${ }^{-}$Ly5.2 $2^{+}$cells were electronically gated and analyzed for Sca1 and c-Kit to define LSK population. (D) Percentage of Ly5.2 LSK cells in total BM of the recipient mice. Data are mean plus or minus SD of 7 mice repopulated with Wt cells and 3 mice repopulated with Wnt3a ${ }^{-/-}$cells. Results are representative of 3 independent experiments.

of Ly5.2 LSKs in the BM of mice receiving Wnt3a $a^{-1-}$ cells (Figure 2D). Flt3 ${ }^{-}$and Flt3 ${ }^{+}$subsets within LSK compartment did not differ between the mice receiving Wt or Wnt $3 \mathrm{a}^{-1-}$ LSKs (data not shown).

However, when total BM cells from the primary recipient mice were retransplanted into lethally irradiated Wt secondary recipients, the repopulation capacity measured in peripheral blood was severely reduced in mice receiving $W n t 3 a^{-1-}$ cells, as early as 4 weeks after transplantation (Figure 3A). Furthermore, the contribution toward different lineages was strongly affected in the secondary recipients receiving $\mathrm{Wnt}_{3} \mathrm{a}^{-/-}$cells (Figure $3 \mathrm{~B}$ ). Analy- sis of the repopulation efficiency in BM 13 weeks after transplantation showed an average contribution of $60 \%$ in the mice that received retransplanted $\mathrm{Wt}$ cells whereas in the mice receiving retransplanted $\mathrm{Wnt} 3 \mathrm{a}^{-1-}$ cells this was reduced more than 15 -fold ( $4 \%$ chimerism on average; Figure 3C,D). Moreover, although the total percentage of LSKs did not differ in the mice receiving Wnt $3 \mathrm{a}^{-1-}$ cells, this population mainly consisted of cells expressing the congenic marker Ly5.1, while around 70\% (average) of the LSKs from the Wt mice group expressed the Ly5.2 marker (Figure $3 \mathrm{E}, \mathrm{F})$. The analysis performed in other hematopoietic organs such as thymus and spleen showed similar differences (data not
A

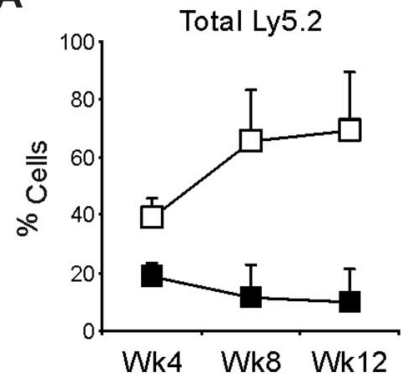

B

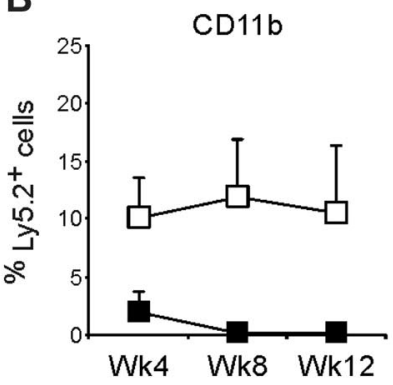

$\mathrm{E}$

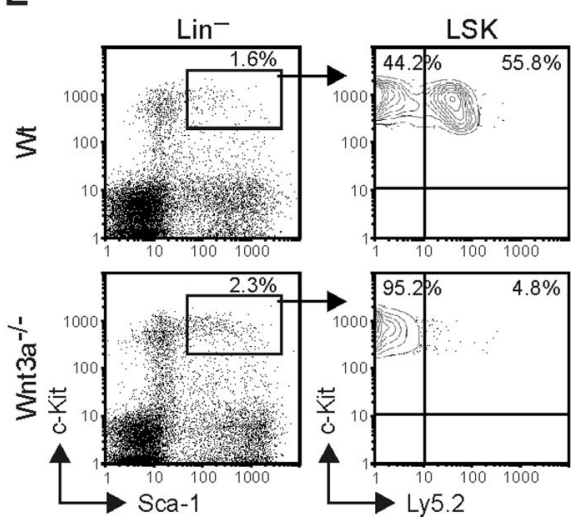

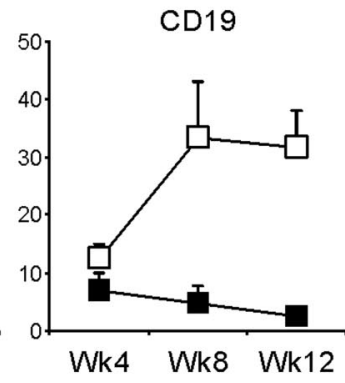

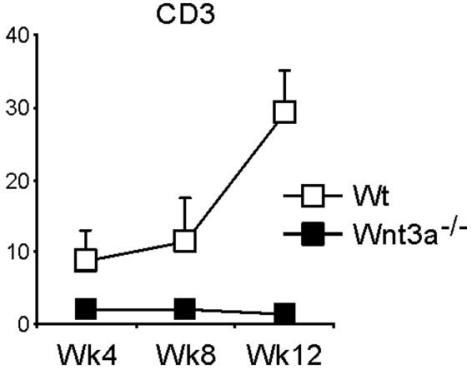

$\mathbf{F}$

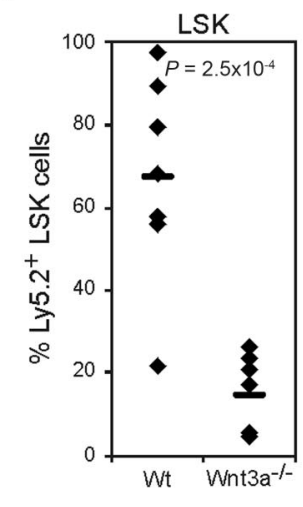

Figure 3. Wnt3a-l- $\mathrm{HSC}$ have severely reduced long-term repopulation capacity as revealed by failure to repopulate secondary recipients. Total BM cells from primary recipient mice were retransplanted into lethally irradiated secondary Ly5.1 recipients. (A) Repopulation efficiency was analyzed in peripheral blood at the indicated time

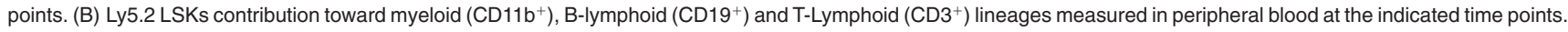
$(A, B)$ Graphs show mean plus or minus SD of 7 mice in each group (Wt and Wnt3a ${ }^{-1-}$ ). (C) Thirteen weeks after transplantation repopulation was analyzed in the hematopoietic organs. Numbers in quadrants indicate the percentage of total Ly5.1 or Ly5.2 cells in the BM of the recipient mice. CD45.1-CD45.2- double negative cells constitute erythrocytes and megakaryocytes. (D) Percentage of total Ly5.2 cells in the BM of the recipient mice. The averages are indicated by a dash. (E) HSC compartment analysis in the secondary recipient mice. LSK cells were gated and analyzed for Ly5.2 expression. (F) Frequency of Ly5.2 LSK cells in the BM of the recipient mice. The averages are indicated by a dash. (C-F) Data represent 7 mice in each group. $P$ values are indicated in the graphs. Results are representative of 3 independent experiments. 
A

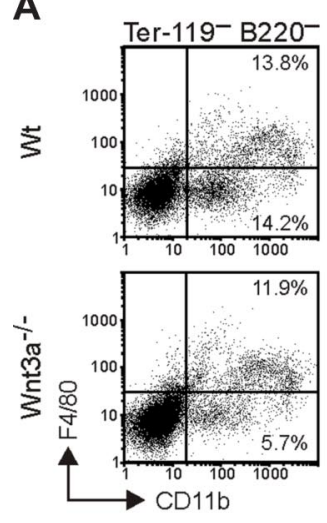

E

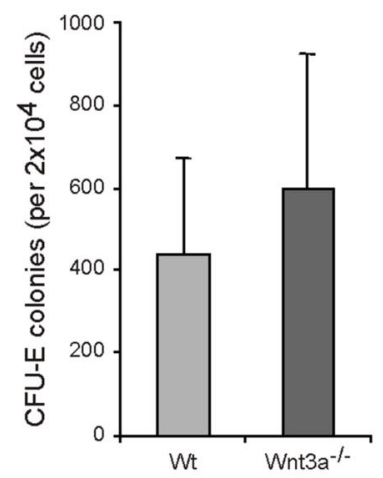

B

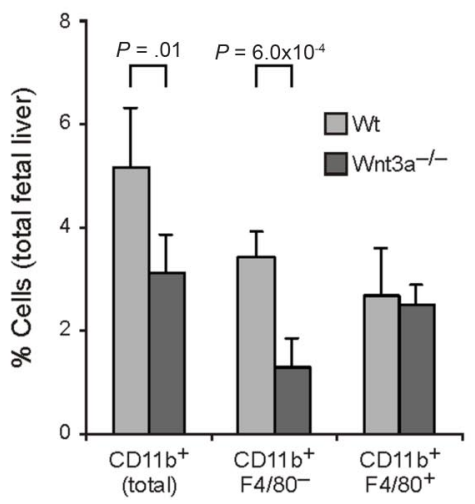

F
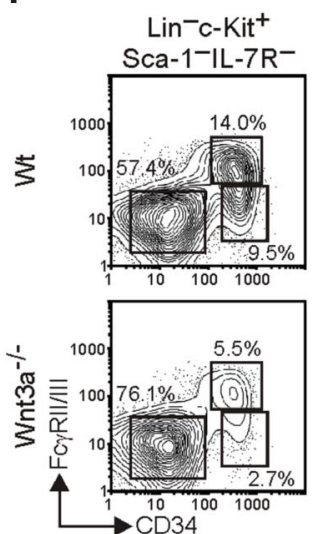

C

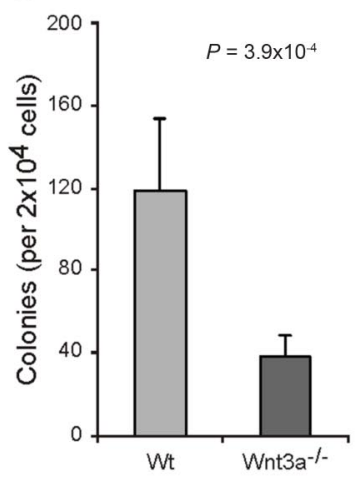

D

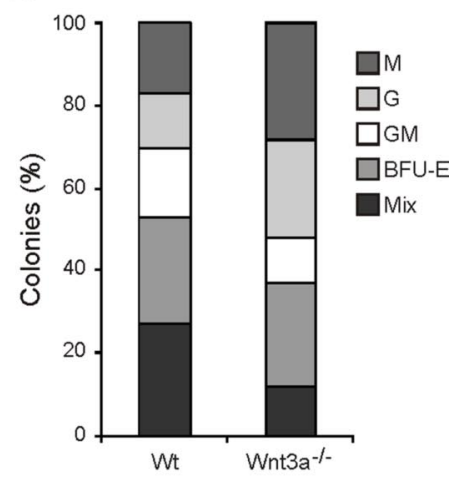

G

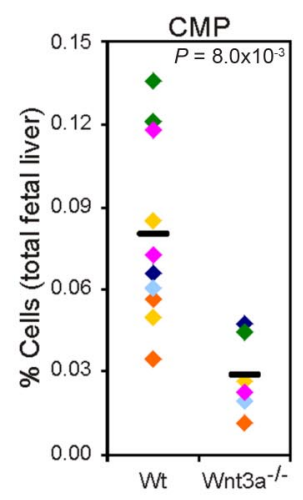

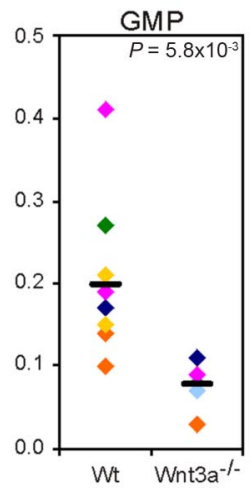

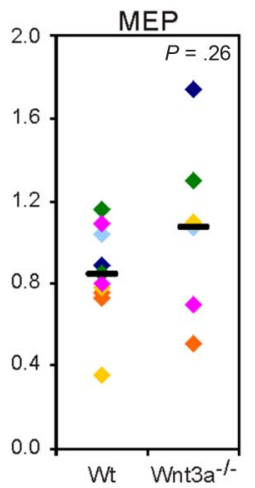

Figure 4. Wnt3a deficiency affects myeloid progenitors without impairing terminal differentiation. (A) E12.5 Wnt3a ${ }^{-1-}$ livers show decreased frequency of myeloid $\mathrm{CD}_{11 \mathrm{~b}^{+}}$(Mac1) and $\mathrm{CD} 11 \mathrm{~b}^{+} \mathrm{F} 4 / 80^{-}$immature subsets, accessed by flow cytometric analysis. Numbers in quadrants denote frequencies of cells gated as indicated. (B) Frequency of CD11 b ${ }^{+}$myeloid cells and F4/80 (+/-) subsets in total FL. Data are mean plus or minus SD of 5 Wt and 4 Wnt3a ${ }^{-1-}$ FLs, from 3 different litters. (C) Numbers of colonies yielded by Wt and Wnt3a ${ }^{-1-}$ FLs in methilcelulose colony assays. Data are mean plus or minus SD of 6 Wt and 3 Wnt3a ${ }^{-1-}$ FLs, from 3 different litters, done in triplicate. $P=3.9 \times 10^{-4}$. (D) Relative frequency of the different colonies determined by morphologic analysis and confirmed by staining with May-Grunwald Giemsa. Data are representative of $4 \mathrm{Wt}$ and $3 \mathrm{Wnt} 3 \mathrm{a}^{-1-} \mathrm{FLs}$, from 3 different litters. M, Macrophage; G, granulocyte; BFU-E, burst forming unit-erythrocyte; Mix, mixed (containing at least 3 different types of cells). (E) Erythroid colony-forming unit (CFU-E) assay of Wt and Wnt3a ${ }^{-/-}$FLs cells. Data are mean plus or minus SD of 5 Wt and 4 Wnt3a ${ }^{-/-}$FLs, from 3 different litters, done in triplicate. (F) Flow cytometry analysis of myeloid progenitor subsets in the FL of Wt and Wnt3a ${ }^{-1-}$ embryos. Lineage-negative cells were electronically gated and analyzed for c-Kit, Sca1 and IL-7R expression. C-Kit ${ }^{+}$Sca1- IL-7R ${ }^{-}$cells were then analyzed for CD34 and Fc $\gamma R$ II/III expression. Numbers next to outlined areas indicate the percentage of cells in each progenitor subset (CMP-Fc $\gamma R^{10} \mathrm{CD} 34^{+}$; GMP-Fc $\gamma \mathrm{R}^{\text {hi }} \mathrm{CD} 34^{+}$; MEP-Fc $\gamma \mathrm{R}^{\mathrm{lo}} \mathrm{CD} 34^{-}$). (G) Frequency of CMPs, GMPs, and MEPs in total $\mathrm{FL}$. The averages are indicated by a dash. Data from $11 \mathrm{Wt}$ and $6 \mathrm{Wnt} 3 \mathrm{a}^{-/-} \mathrm{FLs}$, belonging to 6 different litters identified by different colors. $P$ values are indicated.

shown). Thus, secondary transplantations revealed strongly reduced reconstitution by $\mathrm{Wnt} 3 \mathrm{a}^{-/-} \mathrm{HSCs}$, showing that these cells have extremely limited self-renewal capacity. Importantly, although being transplanted into $\mathrm{Wt}$ recipient mice, in which Wnt3a is abundantly expressed in BM, ${ }^{16}$ the LSK cells had very low repopulation efficiency, indicating a permanent and irreversible self-renewal deficiency.

\section{Wnt3a-I- HSC have normal differentiation capacity}

At E12.5, FL hematopoiesis is mainly directed toward erythrocyte production, with around $95 \%$ of the cells constituting erythroid progenitors. Analysis of the different stages of erythroid development using the erythroid-specific marker Ter119 and the transferrin receptor $\mathrm{CD} 71^{26}$ together with the progenitor marker c-Kit, showed no significant differences between Wt and Wnt $3 \mathrm{a}^{-1-}$ FLs, indicating normal erythroid development (data not shown). Analysis of the nonerythroid lineages $\left(\mathrm{CD} 71^{-}\right.$Ter $\left.119^{-}\right)$showed that in the $\mathrm{Wnt} 3 \mathrm{a}^{-1-}$ livers the $\mathrm{B} 220^{+}$cells were also present in a similar frequency as in Wt embryos. However, total CD11 ${ }^{+}$myeloid cells were slightly reduced $(P=.01)$ in the livers from Wnt $3 \mathrm{a}^{-1-}$ embryos (Figure 4A,B). Nevertheless this reduction was not observed in the more mature $\mathrm{CD} 11 \mathrm{~b}^{+} \mathrm{F} 4 / 80^{+}$subset of myeloid cells, but it was due to a marked reduction in more immature

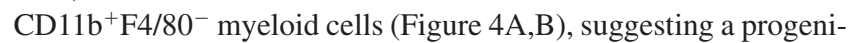
tor deficiency that does not impair terminal differentiation.

\section{Reduced numbers of myeloid but not B-lymphoid progenitors}

The decreased frequency of more immature myeloid cells, together with the strong reduction of MPPs indicated that Wnt3a deficiency is affecting not only HSC self-renewal but also primitive progenitors subsets.

To further investigate a possible deficiency in myeloid progenitors, in vitro methylcellulose colony-forming assays were performed. Interestingly, in the presence of multiple cytokines, compared with wild-type cells, the Wnt $3 a^{-1-}$ FL cells consistently yielded $>3$-fold fewer colonies (Figure 4C). Of interest, the relative frequency of the different types of colonies was also different between the Wt and Wnt $3 \mathrm{a}^{-1-}$ cells (Figure 4D). Wnt $3 \mathrm{a}^{-1-}$ FL cells yielded a lower number of CFU-Mix leading to a 6-fold reduction in the absolute numbers of these colonies. Besides this, also CFU-GM and BFU-E colonies appeared slightly reduced. In agreement with what was previously observed, absolute numbers of CFU-G and -M were not significantly different, indicating that more mature myeloid cells were produced at normal frequencies. 
Figure 5. Lymphoid potential of Wnt3a-1- hematopoietic progenitors. (A) Flow cytometric analysis of common lymphocyte progenitors (CLPs). Lineage-negative $\mathrm{IL}-7 \mathrm{R}^{+}$cells were gated and analyzed for C-Kit and Sca1 expression. Numbers indicate the percentage of cells in each gate. (B) Percentage of CLPs in total FLs from Wt and $W n t 3 a^{-1-}$ embryos. The averages are indicated by a dash. Data from $11 \mathrm{Wt}$ and $6 \mathrm{Wnt} 3 \mathrm{a}^{-/-} \mathrm{FLs}$, belonging to 6 different litters identified by different colors. (C) To evaluate B-cell potential Wt and Wnt $3 a^{-1-}$ FL cells were cultured for 7 days on confluent layers of OP9 BM derived stromal cells. Cells were harvested and presence of cells from different lineages was analyzed by flow cytometry. Data are representative of 4 independent experiments. (D) Reduced cellularity in Wnt3a- ${ }^{-1-}$ thymic anlage revealed by immunohistochemistry analysis. Tissue sections of E12.5 embryos were stained with $\mathrm{HE}$ to visualize different tissues (left panels). Thymic epithelial cells stained with the thymic stroma antibody ER-TR4 (right panels) to confirm identification of thymic anlage in $\mathrm{Wnt} \mathrm{a}^{-1-}$ embryos. Staining with an isotype control for ER-TR4 was completely blank. Thymic anlage is indicated by $\boldsymbol{\nabla}$. Stainings shown are representative of $4 \mathrm{Wt}$

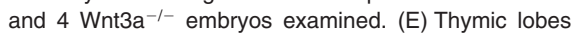
from Wt and Wnt3a ${ }^{-1-}$ E12.5 embryos were cultured in FTOC to allow T-cell development to proceed, and harvested at the indicated time points. Thymocytes subsets were analyzed by flow cytometry. Data are from $5 \mathrm{Wt}$ and $3 \mathrm{Wnt} 3 \mathrm{a}^{-1-}$ embryos analyzed.
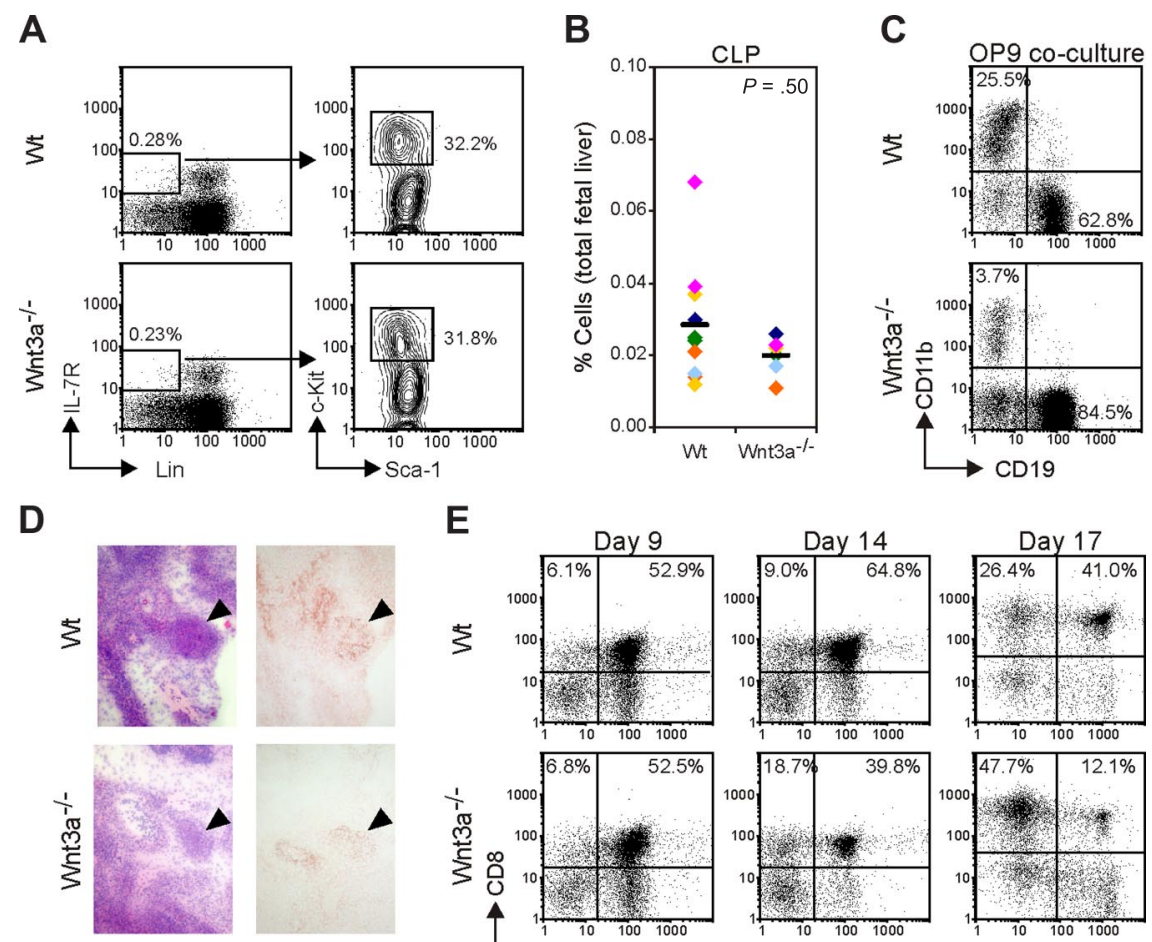

E
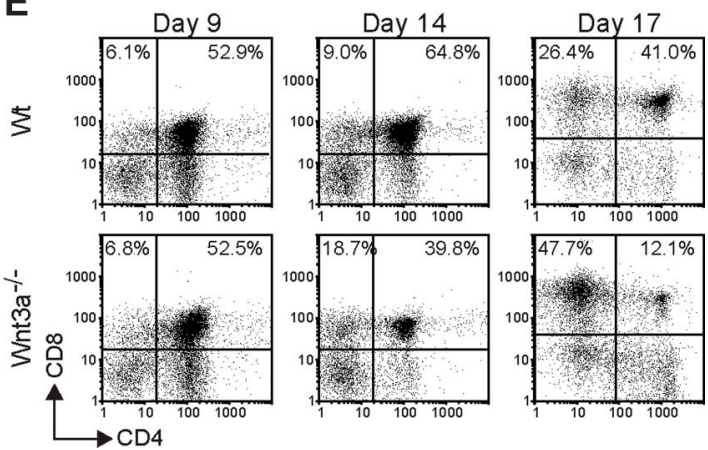

Total number of CFU-E colonies was not significantly altered (Figure 4E). This was confirmed by flow cytometric analysis of the different myeloid progenitor subsets. ${ }^{27}$ Both common myeloid progenitors (CMPs; $\mathrm{Fc} \gamma \mathrm{R}^{\mathrm{lo}} \mathrm{CD} 34^{+}$) and granulocyte-monocyteprogenitors (GMPs; Fc $\gamma \mathrm{R}^{\mathrm{hi}} \mathrm{CD} 34^{+}$) frequencies in $\mathrm{Wnt} 3 \mathrm{a}^{-1-} \mathrm{FLs}$ were severely reduced. Megakaryocyte-erythrocyte progenitors (MEPs; Fc $\gamma \mathrm{R}^{\mathrm{lo}} \mathrm{CD} 34^{-}$) were not affected (Figure 4F,G).

Wnt3a has been proposed to function as a growth factor for pro-B cells when provided as a prototype Wnt in vitro. ${ }^{16}$ Moreover, the severe reduction in the numbers of MPPs suggested that $\mathrm{Wnt}_{3} \mathrm{a}^{-1-}$ primitive progenitors might have reduced lymphoid potential.

Surprisingly, the analysis of the FL counterpart of adult common lymphoid progenitor (CLP), which is phenotypically similar $\left(\mathrm{Lin}^{-} \mathrm{IL}-7 \mathrm{R}^{+} \mathrm{c}-\mathrm{Kit}^{\mathrm{lo}} \mathrm{Sca} 1^{\mathrm{lo}}\right)$ and is present as a distinct population at E12.5, ${ }^{28}$ did not reveal any difference between $\mathrm{Wt}$ and $\mathrm{Wnt} 3 \mathrm{a}^{-1-}$ FLs, although there is a nonsignificant trend toward lower numbers of CLP in Wnt $3 a^{-1-}$ embryos (Figure 5A,B). Furthermore, after 7 days of culture on OP9 BM-derived stromal cells, both Wt or Wnt3a $a^{-1-}$ E12.5 FL cells efficiently developed into $\mathrm{CD} 19^{+} \mathrm{B}$-cell progenitors (Figure $5 \mathrm{C}$ ). Most cells were in the pro-B-cell stage, but after prolonged culturing intracellular IgM could be detected both in the cultures using Wt or Wnt $3 \mathrm{a}^{-1-}$ cells (data not shown). After 7 days of culturing, the percentage of $\mathrm{CD}_{19}{ }^{+}$cells was significantly higher in the Wnt $3 \mathrm{a}^{-1-}$ cultures, but this increase was not reflected by an absolute increase in cell numbers. Rather it was attributed to the marked reduction of the $\mathrm{CD}_{1} 1 \mathrm{~b}^{+}$population, confirming that Wnt3a deficiency negatively affects myeloid differentiation.

We were also interested in the capacity of $W n t 3 a^{-1-}$ progenitors to seed the thymus and differentiate into the T-cell lineage. In the developing mouse embryo, the thymic rudiment is first colonized by immature cells at approximately E11. ${ }^{21}$ Because thymic lobes at E12.5 are not yet well-defined structures, sections were prepared and stained with HE to visualize different tissues. Presence of a thymic rudiment could be demonstrated in Wnt $3 \mathrm{a}^{-1-}$ embryos and was confirmed by staining with ER-TR4, which identifies thymic epithelial cells ${ }^{29}$ (Figure 5D). Although the thymic rudiment is seeded by hematopoietic cells, in Wnt $3 \mathrm{a}^{-1-}$ embryos it shows a noticeable reduction in size indicating that T-cell development is affected with respect to cell numbers. To further characterize this deficiency, explant cultures of E12.5 thymic lobes (fetal thymic organ culture $[\mathrm{FTOC}])$ were performed. In general, Wnt $3 \mathrm{a}^{-/-}$ thymi were found to contain fewer thymocytes (usually about 3 -fold lower) than Wt embryos, irrespective of the duration of culturing (data not shown). After 9 days of culturing, all stages of T-cell development could be distinguished, including mature single positive (SP) $\mathrm{CD}^{+}$and $\mathrm{CD}^{+}$cells, both in $\mathrm{Wt}$ and $\mathrm{Wnt} 3 \mathrm{a}^{-1-}$ embryos (Figure 5E). At this time point, no differences were detected in subset distribution between $\mathrm{Wt}$ and $\mathrm{Wnt} 3 \mathrm{a}^{-1-}$ thymi. However, when thymic lobes were cultured for prolonged times

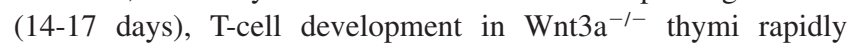
deteriorated. This presented mainly as a decrease in the percentage of double-positive (DP) cells and an accumulation of $\mathrm{CD}^{+}$ thymocytes, revealing a block at the ISP stage (Figure 5E). The progressively impaired T-cell development at the ISP stage phenocopies mice deficient in $T c f 1,{ }^{30}$ suggesting that the Wnt 3 a effects on immature thymocytes are mediated by signaling through Tcf 1 . To investigate whether this defect is intrinsic to the hematopoietic cells that seeded the thymus, we cultured Wt and Wnt $3 \mathrm{a}^{-/-}$E12.5 FL cells in irradiated thymic lobes from Wt E14.5 embryos. After 14 to 21 days of culture, lobes were stained for flow cytometry. No differences were observed between FTOCs using Wt or Wnt3a ${ }^{-1-}$ FL cells, with respect to cell numbers or thymocyte subset distribution (data not shown). The reduced T-cell development in Wnt $3 \mathrm{a}^{-1-}$ embryos must therefore be attributed to absence of Wnt3a production by the thymic stroma.

\section{Wnt3a deficiency does not alter survival or cell cycle of hematopoietic stem and progenitor cells}

Wnt $3 a^{-1-}$ HSCs have impaired long-term repopulation capacity but have largely retained the ability to develop into all hematopoietic 
A

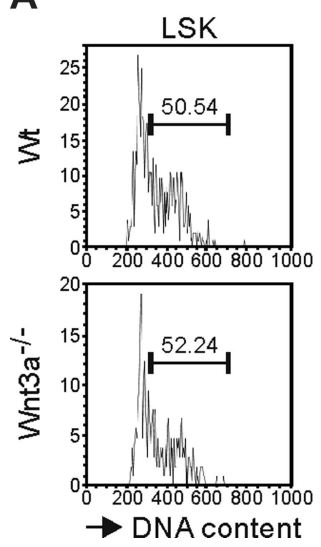

B

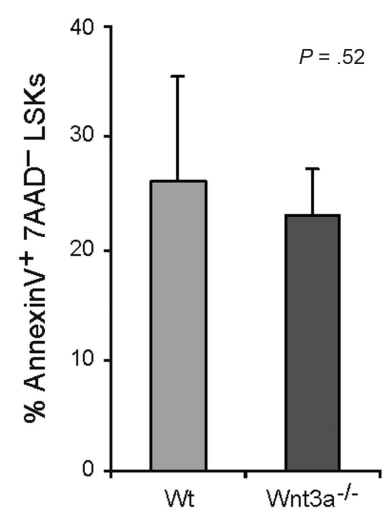

C

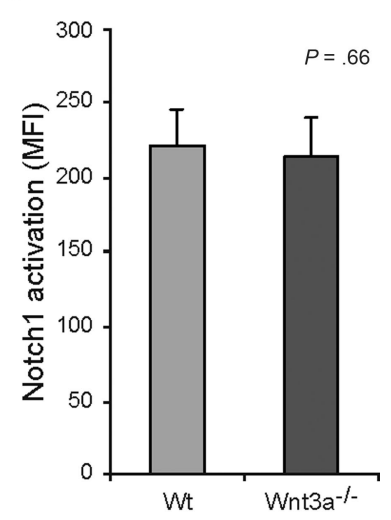

Figure 6. Long-term repopulation deficiency is not caused by altered cell cycle or survival. (A) Cell-cycle analysis (Hoechst 33342) of E12.5 FL LSKs from Wt and Wnt3a $a^{-1-}$ embryos. Values represent percentage of LSK cells in S/G2/M phases of the cell cycle. Results are representative of $3 \mathrm{Wnt} 3 \mathrm{a}^{-1-}$ and $6 \mathrm{Wt}$ embryos from 3 different litters. (B) Determination of percentage of apoptotic cells by staining with annexin $\mathrm{V}$ and 7AAD. Apoptotic cells were defined as annexin $\mathrm{V}^{+} 7 A A D^{-}$. Results are representative of $6 \mathrm{Wnt}^{3} \mathrm{a}^{-1-}$ and $6 \mathrm{Wt}$ embryos from 2 different litters. (C) Activation of Notch1 in E12.5 FL LSKs from Wt and Wnt3a ${ }^{-1-}$ embryos. Results are representative of $4 \mathrm{Wnt}_{3} \mathrm{a}^{-1-}$ and $8 \mathrm{Wt}$ embryos belonging to 4 different litters. lineages. We next sought to study the cellular basis underlying this self-renewal defect.

HSC function depends on a tight regulation of the cell cycle. It was recently shown that activation of $\beta$-catenin leads to an increased proliferation followed by loss of stem cell activity and exhaustion of the HSC pool. ${ }^{8,9}$ We therefore analyzed the cell-cycle status of the HSC compartment. A high proportion of the LSK cells in the Wt FL are in cycle ${ }^{22}$ in agreement with FL being an organ where expansion of the HSC compartment occurs. No significant differences were found in the frequency of LSK cells in S/G2/M suggesting that Wnt3a deficiency has no effect on the HSCs proliferation (Figure 6A). Furthermore, to investigate whether LSKs from Wnt $3 \mathrm{a}^{-1-}$ embryos have decreased survival capacity, we analyzed apoptosis in these cells. In Wt and Wnt $3 a^{-1-}$ LSK compartments, the frequency of annexin $\mathrm{V}^{+}$cells did not differ (Figure 6B) indicating comparable apoptosis levels.

We also wanted to analyze whether Wnt3a deficiency differentially affected activation of the Notch-signaling pathway because this has been shown to be important for HSC function and has been proposed to collaborate with Wnt signaling to maintain stem cell properties. ${ }^{31}$ However using a specific antibody against activated Notch1 no differences were detected in the activation of this pathway in Wnt $3 a^{-1-}$ comparing to Wt LSKs (Figure 6C).

Thus, neither alteration in cell cycle nor in survival of stem/ progenitor cells explains the reduced numbers of cells and decreased long-term repopulation capacity. Furthermore, differential activation of Notch1 was also not observed.

\section{Discussion}

Using a mouse model that lacks expression of Wnt3a, we show here that the deficiency of one specific Wnt protein leads to markedly reduced numbers of HSCs in vivo. These HSCs were not affected in multilineage differentiation potential but they had an irreversible and severely decreased self-renewal and long-term repopulation capacity, as determined by secondary transplantation assays. The absence of Wnt3a also strongly affects the primitive MPP progenitors and more mature myeloid progenitors such as CMPs and GMPs that were decreased in number. By contrast CLPs and precursor B cells were not affected.

Because MPPs retain both myeloid and lymphoid potentials but little or no erythroid-megakaryocyte potential, ${ }^{24,32,33}$ one could expect both myeloid and lymphoid progenitors to be affected. The fact that CMPs are severely reduced while CLP appeared not to be affected shows a stronger dependency on Wnt3a for myeloid versus
B-lymphoid development. This is also supported by the strict dependence on Wnt- $\beta$-catenin signaling for the progression of chronic myelogenous leukemias whereas B-cell acute lymphoblastic leukemias can develop independently of $\beta$-catenin expression. ${ }^{13}$ Despite this deficiency at the progenitor level, mature myeloid cells were present at normal numbers. This can be explained by the fact that the defects observed do not completely block differentiation and because lineage-specific progenitors can probably compensate for the early incomplete differentiation block by rapid and extensive proliferation supported by cytokines that act in a lineage specific fashion, such as GM-, G- and M-CSF, as well as IL-7.

By means of coculture of FL progenitors with a BM derived stromal cell line, no defects in B-cell development were observed. It was previously shown that B-cell development in Lef1 ${ }^{-/-}$mice is partially blocked at the pro-B-cell stage due to lack of Wntdependent proliferation. ${ }^{16}$ In agreement with this, Wnt5a was shown to negatively regulate proliferation of early B cells, possibly by inhibiting canonical-Wnt target genes. ${ }^{34}$ Although recombinant Wnt3a was shown to induce this proliferation in vitro, ${ }^{16}$ it is likely that Wnt3a is not the physiologically relevant Wnt for pro-B-cell proliferation or other Wnt proteins are compensating this function, as our data do not show a block in B-cell development. This is consistent with the idea that HSCs and precursor B cells occupy different niches.

In contrast, the T-cell lineage shows clear defects, probably reflecting the dependency of the early thymic emigrants on MPP as a major physiological precursor cell to the first cell that seeds the thymus. ${ }^{35}$ The progressively impaired T-cell development at the ISP stage observed phenocopies mice deficient in Tcf $1{ }^{30}$ suggesting that in these mice T-cell development is blocked because of lack of a nuclear response to proliferative Wnt signals, as has also been suggested by previous loss $-36,37$ and gain-of-function studies. ${ }^{38}$ This phenotype appears to be environmentally determined, because Wnt $3 a^{-1-}$ cells develop normally in Wt FTOCs. This is supported by the expression of Wnt3a in thymic epithelium, but not in the developing thymocytes. ${ }^{17}$ The similarities with Tcf1 deficiency suggest that Wnt3a is directly regulating thymocyte development, but it is possible that Wnt3a is also important for the thymic stroma and consequently affects T-cell development. Nevertheless, there appears to be an important difference in the function of Wnt3a for immature thymocytes, where it seems to be mainly a proliferation factor, versus HSCs where it influences self-renewal and differentiation cell fates

The Wnt3a deficiency does not only lead to a quantitative defect in HSC numbers, but Wnt $3 a^{-1-}$ HSCs are also functionally affected. Although they are able to efficiently repopulate lethally irradiated 
primary recipients, long-term reconstitution capacity is markedly reduced when HSCs are rechallenged by transplantation into secondary recipient mice, demonstrating a lack in self-renewal capacity.

Because Wnt3a is a secreted factor it might affect HSCs directly or indirectly by signaling through the stromal cells ${ }^{39}$ that constitute the HSC niche. Thus, this environmentally determined deficiency turns into a cell-autonomous defect as Wnt3a in BM of the Wt recipient mice is not able to restore normal HSC function. This indicates that lack of Wnt3a during a critical period in embryonic development irreversibly impairs the self-renewal capacity of HSCs, suggesting that Wnt3a is important for the establishment of a specific genetic program in HSCs. A similar phenotype was observed in adult HSCs when they transiently occupied a niche that overexpressed the Wnt inhibitor Dkk1.40 Furthermore, the increased B-cell proliferation observed in Wnt5a-deficient FLs also could not be complemented by physiologic levels of Wnt5a expressed by Wt BM stroma. ${ }^{34}$ The irreversible Wnt $3 a^{-1-}$ phenotype could possibly be explained by epigenetic alterations induced by Wnt signals. Indeed, different members of the Polycomb complex factors were shown to be essential for HSCs function. ${ }^{41,42}$ More specifically, Rae28 deficiency results in reduced fetal HSC and progenitor numbers, while FL cellularity and mature cell subsets remained unaffected, ${ }^{42}$ similarly to what we observed here.

Several lines of evidence suggest that Wnt activity is context dependent. Wnt proteins have different effects depending on the target cell, ${ }^{34}$ receptor availability, ${ }^{43}$ and probably other signals or pathways activated at the same time. ${ }^{6,44}$ In this way, approaches to generally activate or ablate Wnt signaling may lose the regulatory mechanisms between different Wnts. Indeed different $\beta$-catenin gain-of-function studies yielded different results probably reflecting the effect of different dosages of activation of the pathway. ${ }^{6,8,9}$ The notion that correct levels of Wnt signaling are critical in inducing a self-renewal type of expansion in $\mathrm{HSC}^{45}$ is also supported by experiments from Baba et al, ${ }^{46,47}$ who showed that it is possible to induce some stem cell characteristics in committed progenitors by ectopic expression of stable $\beta$-catenin. However, such progenitors did not reconstitute $\mathrm{T}$ cells when transplanted to immunodeficient mice, showing again that a very strong signal that bypasses all negative regulatory steps of the Wnt-signaling cascade such as given by stabilized $\beta$-catenin cannot mimic events triggered by tightly regulated physiological Wnt signals. Although initial studies failed to show a phenotype in the absence of $\beta$-catenin, ${ }^{10-12} 2$ recent loss of function approaches by knocking out $\beta$-catenin ${ }^{13}$ or overexpressing Dkk $1,{ }^{40}$ thereby inhibiting canonical Wnt signaling, showed reduced self-renewal capacity of HSCs. Here we were able to point one specific Wnt protein in this function, at least during embryonic development.

The reduced number of HSC and reduced long-term repopulation capacity observed could not be explained by alterations in cell cycle or survival of stem/progenitor cells. In this way, HSCs from $W n t 3 a^{-1-}$ embryos seem to be biased to a non-self-renewing type of division leading to depletion of the HSC pool. Several developmentally conserved signaling pathways, including Notch, Hedgehog and Smad pathways, appear to be important in the regulation of HSC function ${ }^{48}$ and may normally collaborate with Wnt signaling in establishing a self-renewal genetic program. One such candidate is Notch signaling. However the levels of activated Notch1 did not differ between Wt and Wnt $3 a^{-1-}$ LSK cells, making it unlikely that Notch1 plays this role.

Interestingly, besides the similarities with $\mathrm{Tcf} 1^{-1-} \mathrm{Lef}^{-1-}$ embryos, ${ }^{18}$ the posterior patterning defects observed in the Wnt $3 a^{-1-}$ embryos also resemble the ones described for the Sox $17^{-1-}$ embryos. Sox17 was recently shown to be a critical regulator of fetal HSCs maintenance. Deletion of Sox17 leads to increased levels of Dkk1 implying that it maintains fetal HSCs by promoting Wnt signaling. ${ }^{49}$

We and others ${ }^{4}$ did not find Wnt $3 a$ expression at detectable levels in the FL, probably because of Wnt3a expression is only present a very restricted subset of niche cells. Nevertheless, this might indicate that the deficiency we report here is determined earlier during the embryonic development or in extrahepatic HSC sources. Because the numbers of definitive HSCs in E12.5 FL results from the cumulative HSC activity from the aorta-gonadmesonephros (AGM) region, yolk sac, and placenta, ${ }^{21,50}$ these tissues warrant future study.

Given the differences between fetal and adult hematopoiesis, it is also important to investigate whether Wnt3a plays similar roles in the self-renewal of BM HSC. In view of the fact that Wnt3a is expressed in $\mathrm{BM},{ }^{16}$ such a functional role would not be unexpected. Finding specific Wnt proteins that regulate hematopoietic stem cell fate may have important implications for in vitro manipulation and expansion of the HSC compartment for transplantation and gene therapy applications as well as for the understanding of cancer stem cells in hematologic malignancies.

\section{Acknowledgments}

The authors thank Prof Dr Leonor Parreira for useful discussions. The authors are grateful to Karin Pike-Overzet, Peter Ng, Tom Schonewille, and Martijn Brugman for helping with various experiments. Dr Terry Yamaguchi is gratefully acknowledged for providing $\mathrm{Wnt}_{3} \mathrm{a}^{-1-}$ mice. Marieke Comans-Bitter is acknowledged for preparing the figures.

T.C.L. is supported by Fundação para a Ciência e a TecnologiaPortugal. F.J.T.S. is supported in part by the Association of International Cancer Research (AICR).

\section{Authorship}

Contribution: T.C.L. and F.W. designed and performed experiments and wrote the manuscript; B.A.E.N., M.R.M.B., E.F.E.d.H., T.N., and S.H. performed experiments; R.d.H. contributed essential analytical tools; J.J.M.v.D. wrote the manuscript; and F.J.T.S. designed experiments, wrote the manuscript, and supervised the project.

Conflict-of-interest disclosure: The authors declare no competing financial interests.

Correspondence: Dr Frank J. T. Staal, PhD, Department of Immunology, Room Ee838, Erasmus University Medical Center, Rotterdam, The Netherlands; e-mail: f.staal@erasmusmc.nl.

\section{References}

1. Rattis FM, Voermans C, Reya T. Wnt signaling in the stem cell niche. Curr Opin Hematol. 2004;11: 88-94.

2. Reya T, Clevers H. Wnt signalling in stem cells and cancer. Nature. 2005;434:843-850.
3. Staal FJ, Luis TC, Tiemessen MM. WNT signalling in the immune system: WNT is spreading its wings. Nat Rev Immunol. 2008;8:581-593.

4. Austin TW, Solar GP, Ziegler FC, Liem L, Matthews W. A role for the Wnt gene family in he- matopoiesis: expansion of multilineage progenitor cells. Blood. 1997;89:3624-3635.

5. Van Den Berg DJ, Sharma AK, Bruno E, Hoffman R. Role of members of the Wnt gene family in human hematopoiesis. Blood. 1998;92:3189-3202. 
6. Reya T, Duncan AW, Ailles L, et al. A role for Wnt signalling in self-renewal of haematopoietic stem cells. Nature. 2003;423:409-414.

7. Willert K, Brown JD, Danenberg E, et al. Wnt proteins are lipid-modified and can act as stem cell growth factors. Nature. 2003;423:448-452.

8. Kirstetter P, Anderson K, Porse BT, Jacobsen SE, Nerlov C. Activation of the canonical Wnt pathway leads to loss of hematopoietic stem cell repopulation and multilineage differentiation block. Nat Immunol. 2006;7:1048-1056.

9. Scheller M, Huelsken J, Rosenbauer F, et al. Hematopoietic stem cell and multilineage defects generated by constitutive beta-catenin activation. Nat Immunol. 2006;7:1037-1047.

10. Cobas M, Wilson A, Ernst B, et al. Beta-catenin is dispensable for hematopoiesis and lymphopoiesis. J Exp Med. 2004;199:221-229.

11. Jeannet G, Scheller M, Scarpellino L, et al. Longterm, multilineage hematopoiesis occurs in the combined absence of beta-catenin and gammacatenin. Blood. 2008;111:142-149.

12. Koch U, Wilson A, Cobas M, Kemler R, Macdonald HR, Radtke F. Simultaneous loss of beta- and gamma-catenin does not perturb hematopoiesis or lymphopoiesis. Blood. 2008;111: 160-164.

13. Zhao C, Blum J, Chen A, et al. Loss of beta-catenin impairs the renewal of normal and CML stem cells in vivo. Cancer Cell. 2007;12:528-541.

14. Staal FJ, Sen JM. The canonical Wnt signaling pathway plays an important role in lymphopoiesis and hematopoiesis. Eur J Immunol. 2008;38: 1788-1794.

15. Takada S, Stark KL, Shea MJ, Vassileva G McMahon JA, McMahon AP. Wnt-3a regulates somite and tailbud formation in the mouse embryo. Genes Dev. 1994;8:174-189.

16. Reya T, O'Riordan M, Okamura R, et al. Wnt sig naling regulates $\mathrm{B}$ lymphocyte proliferation through a LEF-1 dependent mechanism. Immunity. 2000;13:15-24.

17. Weerkamp F, Baert MR, Naber BA, et al. Wnt signaling in the thymus is regulated by differential expression of intracellular signaling molecules. Proc Natl Acad Sci U S A. 2006;103:3322-3326.

18. Galceran J, Farinas I, Depew MJ, Clevers H, Grosschedl R. Wnt3a-like phenotype and limb deficiency in Lef1(-/-)Tcf1(-/-) mice. Genes Dev. 1999;13:709-717.

19. Galceran J, Hsu SC, Grosschedl R. Rescue of a Wnt mutation by an activated form of LEF-1: regulation of maintenance but not initiation of Brachyury expression. Proc Natl Acad Sci U S A. 2001;98:8668-8673.

20. Okamura RM, Sigvardsson M, Galceran J, Verbeek S, Clevers H, Grosschedl R. Redundant regulation of $\mathrm{T}$ cell differentiation and TCRalpha gene expression by the transcription factors LEF-1 and TCF-1. Immunity. 1998;8:11-20.

21. Dzierzak E, Speck NA. Of lineage and legacy: the development of mammalian hematopoietic stem cells. Nat Immunol. 2008;9:129-136.

22. Morrison SJ, Hemmati HD, Wandycz AM Weissman IL. The purification and characterization of fetal liver hematopoietic stem cells. Proc Natl Acad Sci U S A. 1995;92:10302-10306.

23. Adolfsson J, Borge OJ, Bryder D, et al. Upregulation of Flt3 expression within the bone marrow Lin(-)Sca1(+)c-kit(+) stem cell compartment is accompanied by loss of self-renewal capacity. Immunity. 2001;15:659-669.

24. Månsson R, Hultquist $\mathrm{A}$, Luc $\mathrm{S}$, et al. Molecular evidence for hierarchical transcriptional lineage priming in fetal and adult stem cells and multipotent progenitors. Immunity. 2007;26:407-419.

25. Christensen JL, Weissman IL. Flk-2 is a marker in hematopoietic stem cell differentiation: a simple method to isolate long-term stem cells. Proc Nat Acad Sci U S A. 2001;98:14541-14546.

26. Zhang J, Socolovsky M, Gross AW, Lodish HF. Role of Ras signaling in erythroid differentiation of mouse fetal liver cells: functional analysis by a flow cytometry-based novel culture system. Blood. 2003;102:3938-3946.

27. Traver D, Miyamoto T, Christensen J, IwasakiArai J, Akashi K, Weissman IL. Fetal liver myelopoiesis occurs through distinct, prospectively isolatable progenitor subsets. Blood. 2001;98:627-

28. Mebius RE, Miyamoto T, Christensen J, et al. The fetal liver counterpart of adult common lymphoid progenitors gives rise to all lymphoid lineages, CD45+CD4+CD3- cells, as well as macrophages. J Immunol. 2001;166:6593-6601.

29. Van Vliet E, Melis M, Van Ewijk W. Monoclonal antibodies to stromal cell types of the mouse thymus. Eur J Immunol. 1984:14:524-529.

30. Verbeek S, Izon D, Hofhuis F, et al. An HMG-boxcontaining $\mathrm{T}$-cell factor required for thymocyte differentiation. Nature. 1995;374:70-74.

31. Duncan AW, Rattis FM, DiMascio LN, et al. Integration of Notch and Wnt signaling in hematopoietic stem cell maintenance. Nat Immunol. 2005;6: 314-322.

32. Lai AY, Kondo M. Asymmetrical lymphoid and my eloid lineage commitment in multipotent hematopoietic progenitors. J Exp Med. 2006;203:1867 1873

33. Yoshida T, Ng SY, Zuniga-Pflucker JC Georgopoulos K. Early hematopoietic lineage restrictions directed by Ikaros. Nat Immunol. 2006;7:382-391.

34. Liang $\mathrm{H}$, Chen $\mathrm{Q}$, Coles $\mathrm{AH}$, et al. Wnt5a inhibits $B$ cell proliferation and functions as a tumor suppressor in hematopoietic tissue. Cancer Cell. 2003;4:349-360.

35. Bhandoola A, Sambandam A. From stem cell to $T$ cell: one route or many? Nat Rev Immunol. 2006 6:117-126.

36. Staal FJ, Meeldijk J, Moerer P, et al. Wnt signaling is required for thymocyte development and activates Tcf-1 mediated transcription. Eur J Immunol. 2001;31:285-293.

37. Xu Y, Banerjee D, Huelsken J, Birchmeier W, Sen $\mathrm{JM}$. Deletion of beta-catenin impairs T cell development. Nat Immunol. 2003;4:1177-1182.

38. Staal FJ, Weerkamp F, Baert MR, et al. Wnt target genes identified by DNA microarrays in immature CD34 + thymocytes regulate proliferation and cell adhesion. J Immunol. 2004;172:10991108

39. Yamane T, Kunisada T, Tsukamoto H, et al. Wnt signaling regulates hemopoiesis through stroma cells. J Immunol. 2001;167:765-772.

40. Fleming HE, Janzen V, Lo Celso C, et al. Wnt signaling in the niche enforces hematopoietic stem cell quiescence and is necessary to preserve self-renewal in vivo. Cell Stem Cell. 2008;2:274283.

41. Iwama A, Oguro H, Negishi M, et al. Enhanced self-renewal of hematopoietic stem cells mediated by the polycomb gene product Bmi-1. Immunity. 2004;21:843-851.

42. Ohta H, Sawada A, Kim JY, et al. Polycomb group gene rae28 is required for sustaining activity of hematopoietic stem cells. J Exp Med. 2002;195: 759-770.

43. Mikels AJ, Nusse R. Purified Wnt5a protein activates or inhibits beta-catenin-TCF signaling depending on receptor context. PLoS Biol. 2006;4: e115.

44. Nemeth MJ, Topol L, Anderson SM, Yang Y Bodine DM. Wnt5a inhibits canonical Wnt signaling in hematopoietic stem cells and enhances repopulation. Proc Natl Acad Sci U S A. 2007; 104:15436-15441.

45. Trowbridge JJ, Moon RT, Bhatia M. Hematopoietic stem cell biology: too much of a Wnt thing. Nat Immunol. 2006;7:1021-1023.

46. Baba Y, Garrett KP, Kincade PW. Constitutively active beta-catenin confers multilineage differentiation potential on lymphoid and myeloid progenitors. Immunity. 2005;23:599-609.

47. Baba Y, Yokota T, Spits H, Garrett KP, Hayashi S, Kincade PW. Constitutively active beta-catenin promotes expansion of multipotent hematopoietic progenitors in culture. J Immunol. 2006;177: 2294-2303.

48. Blank U, Karlsson G, Karlsson S. Signaling pathways governing stem-cell fate. Blood. 2008;111: 492-503.

49. Kim I, Saunders TL, Morrison SJ. Sox17 dependence distinguishes the transcriptional regulation of fetal from adult hematopoietic stem cells. Cell. 2007; 130:470-483.

50. Kumaravelu P, Hook L, Morrison AM, et al. Quantitative developmental anatomy of definitive haematopoietic stem cells/long-term repopulating units (HSC/RUs): role of the aorta-gonad-mesonephros (AGM) region and the yolk sac in colonisation of the mouse embryonic liver. Development. 2002;129:4891-4899. 